DOI: $10.12731 / 2306-1561-2013-4-22$

\title{
MODELLING OF TRANSPORT SUPPLY CHAIN PARTS AND COMPONENTS TO THE DEALER NETWORKS
}

Lazarenko A.V., Moiseev A.N., Rogova O.B., Solntsev A.A.

\section{Abstract}

The article discusses the construction of software and modeling complex decision support system for organizing the supply of components to the automotive dealer network industry.

We solve the problem of formalized representation of the processes in the supply chain distribution network, followed by the modeling of transport schemes.

Keywords: modeling, supply chain, dealer network, planning, SADT-model.

\section{УДК 681.3}

\section{МОДЕЛИРОВАНИЕ ТРАНСПОРТНЫХ СХЕМ ПОСТАВОК ЗАПАСНЫХ ЧАСТЕЙ И КОМПЛЕКТУЮЩИХ В ДИЛЕРСКИХ СЕТЯХ}

\section{Лазаренко А.В., Моисеев А.Н., Рогова О.Б., Солнцев А.А.}

\section{Аннотация}

В статье рассматриваются вопросы построения программно-моделирующего комплекса системы поддержки принятия решений по организации поставок комплектующих в дилерской сети предприятий автомобильной промышленности.

Решается задача формализованного представления процессов управления поставками в дилерской сети с последующим моделированием транспортных схем.

Ключевые слова: моделирование, схема поставок, дилерская сеть, планирование, SADT-модель.

\section{Структура и состав АСУ планирования поставок}

Процесс взаимодействия подсистемы формирования и контроля поставок с другими подсистемами заключается в их интеграции и интерфейсном согласовании, что схематично представлено на рисунке 1.

Подсистема планирования продаж является поставщиком данных необходимых для формирования плана цепочек поставок [1 - 16].

Подсистема обеспечения взаимодействия поставщиков является поставщиком данных, необходимых для расчета плана цепочек поставок. Это данные о поставщиках, 
производственных мощностях поставщиков, времени доставки и производства, ограничения (например, договорные обязательства).

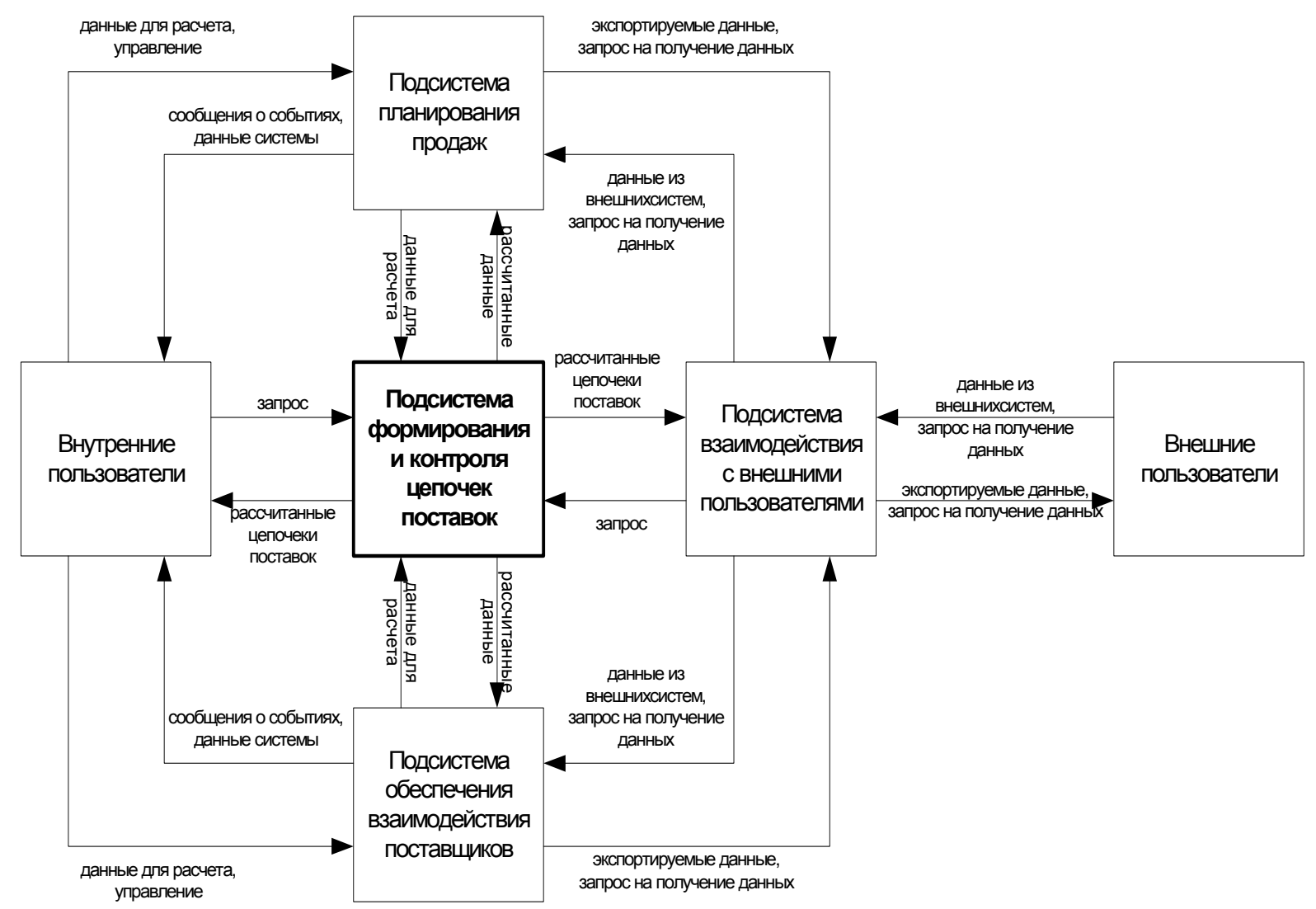

Рисунок 1 - Укрупненная структурная схема АСУ планирования поставок

Подсистема взаимодействия с внутренними пользователями передает запрос на выполнение расчета плана цепочек поставок, на основе данных подсистем «Планирования продаж» и «Обеспечения взаимодействия поставщиков». Пользователь является поставщиком корректирующей информации, необходимой для контроля работы подсистемы «формирования и контроля цепочек поставок». и потребителем подсистемы «Формирования и контроля цепочек поставок». Подсистема предоставляет пользователю рассчитанный план цепочек поставок по заданным параметрам.

\section{Описание бизнес-процессов}

На основе формального описания реализованы схемы описания бизнес-процессов «Формирование плана закупок», разработаны методы и модели оценки эффективности стратегий управления закупками комплектующих в плане реализации ценовых механизмов.

Одной из основных производственных функций предприятия по ремонту и техническому обслуживанию транспортных и технологических машин является функция «Планирование закупок запчастей» $[1,3,12,13]$. 


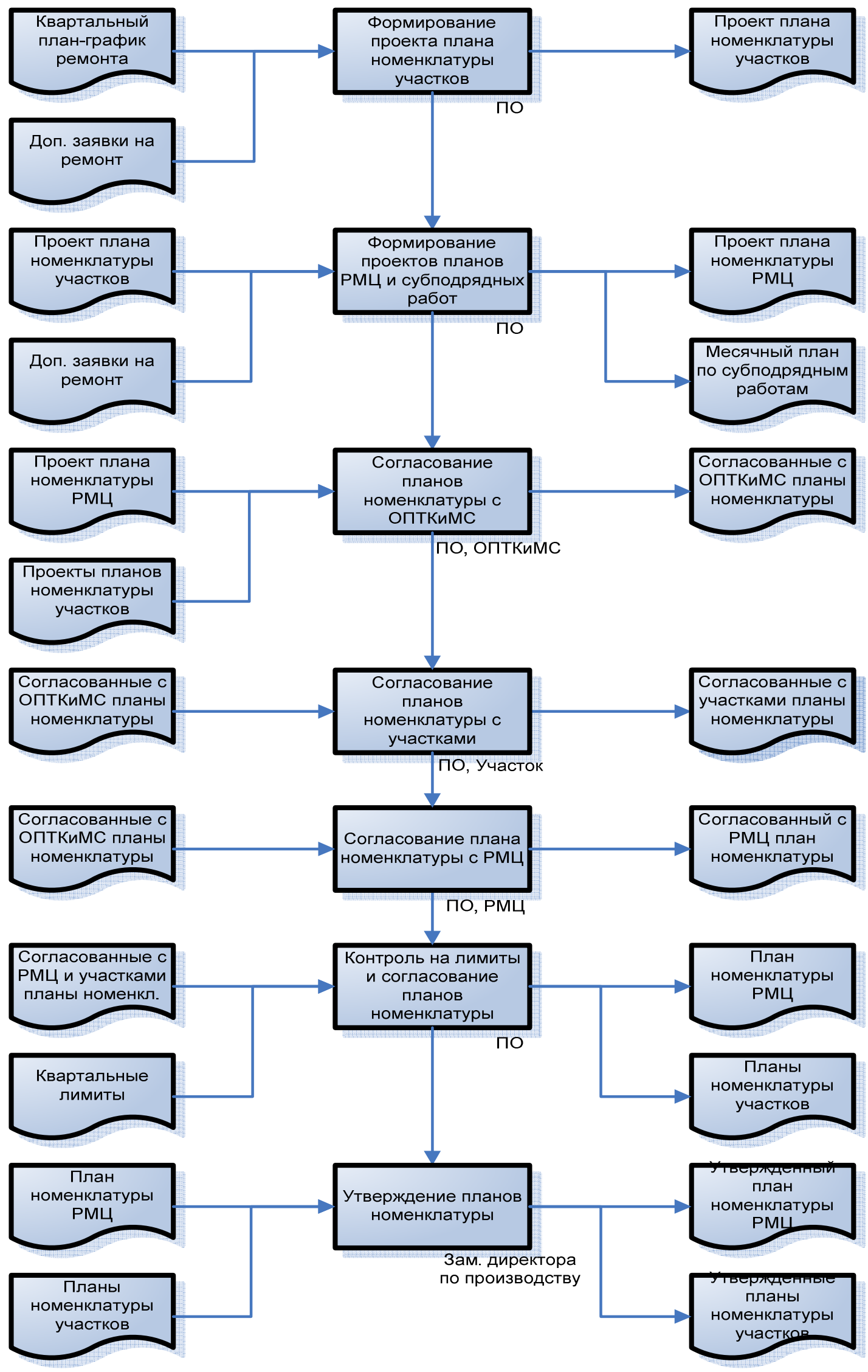

Рисунок 2 - Пример бизнес-процесса формирования плана потребностей в запчастях 
Эта функция включает подготовку и формирование среднесрочного планаграфика поставки запчастей; контроль исполнения среднесрочного плана-графика поставки запчастей; оперативную корректировку среднесрочного плана закупок запчастей; выполнение плана поставок в разрезе Поставщиков (графики поставки) и в разрезе Заказчиков (планы по номенклатуре) и т.д.

Для реализации данной функции в диссертации разработаны схемы описания бизнес-процессов «Формирование плана потребностей в запчастях на основные заказы» (рисунок 2) [1, 3, 5, 10, 12, 13].

Бизнес-процесс формирования плана потребностей в запчастях на основные заказы включает бизнес-функции:

- формирование списка необходимых запчастей;

- формирование плана потребностей в запчастях и другие.

Бизнес-процесс регистрации потребности в запчастях и товарно-материальных ценностях (ТМЦ) включает бизнес-функции:

- формирование сводного реестра заявок на ТМЦ;

- подготовка вариантов ценовых предложений;

- выбор поставщика;

- формирование общей потребности в ТМЦ и потребности в финансах на их приобретение и другие.

Приведенные бизнес-процессы составляют основу решения задачи выбора поставщиков, составления плана-графика закупки запчастей, что непосредственно определяет стратегию закупок и ценовую политику с заказчиками.

В качестве основного требования принимается безусловное выполнение графика поставок и выполнения работ заказчикам (считаем, что санкции за срыв поставок превышают возможную экономию от уменьшения издержек на хранение и процентов за кредит).

\section{Подсистема планирования поставок}

Для формального описания компонентов системы использовалась SADT- модель $[10,17]$. Основным рабочим элементом при создании модели являются диаграммы. Диаграммы содержат блоки и дуги. Блоки изображают функции моделируемой системы. Дуги связывают блоки вместе и отображают взаимодействие между ними. Между объектами и функциями определены четыре типа отношения: вход, управление, выход, механизм.

SADT-модель является иерархически организованной совокупностью диаграмм последовательно детализирующих функции системы до необходимого уровня сложности.

Целью разработки модели является описание процесса функционирования подсистемы «Формирования и контроля поставок». Контекстная диаграмма управления поставками представлена на рисунке 3. 
Входные данные: <данные о производстве>, <данные из внешних систем>, <запрос на получение данных>, <Запрос на выполнение расчета плана цепочек поставок>, <Сведения о продажах> и др.

Выходные данные: <данные во внешние системы>, <параметры продукции>, <план цепочек поставок>, <сообщения во внешние системы>, и др.

Входы по управлению: <правила формирования и управления цепочками поставок>, <алгоритм построения плана> и др.

Механизмы: <автоматизированный программный комплекс>, <пользователи системы> и др.

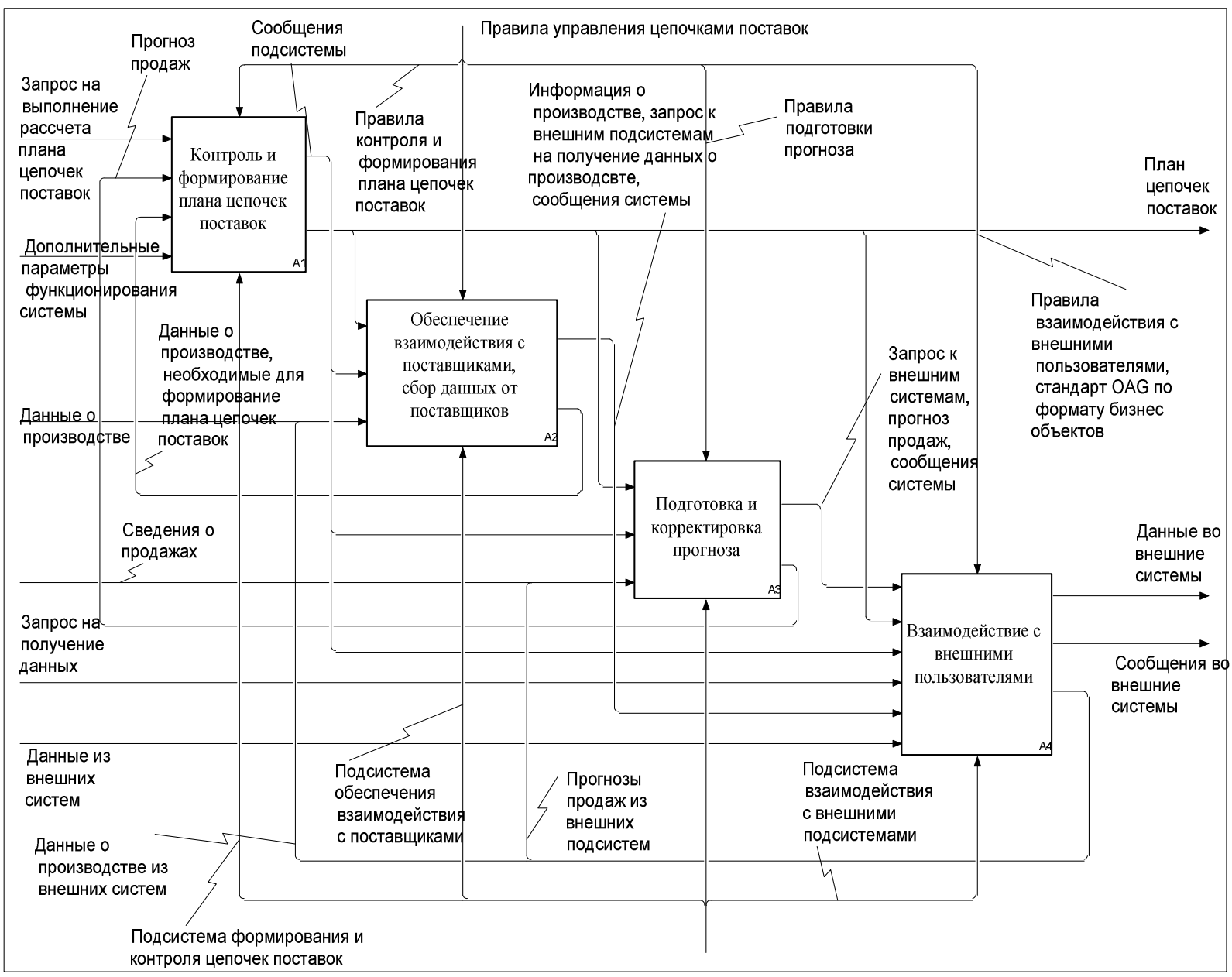

Рисунок - 3 Управление поставками

\section{Заключение}

Построенная формальная модель описания процессов управления поставками, с одной стороны, дает основу непосредственно проектированию АСУ, a c другой стороны, дает возможность параметризации аналитических и имитационных моделей, которые позволяют получить расчетные времена и затраты на реализацию производственного цикла. 


\section{Список информационных источников}

[1] Солнцев А.А., Якунин П.С., Дицкий В.А., Травкин А.М. Решение уравнения баланса в декомпозиционном методе моделирования транспортных потоков. // Методы управления потоками в транспортных системах: сб. науч. тр. МАДИ. Ротапринт МАДИ. - М., 2009 . - С. 17 - 23.

[2] Катырин С.Н., Солнцев А.А., Тимофеев П.А., Якунин П.С. Агрегированные критерии эффективности бизнес-процессов управления производственным циклом промышленных предприятий / // Вестник МАДИ. - М.: МАДИ, 2011. Вып. 4 (27)- С. 5359.

[3] Николаев А.Б., Солнцев А.А., Саная А.Г., Якунин П.С. Методы организации и моделирования дилерских сетей // В мире научных открытий. - Красноярск: НИЦ, 2012. - № 12 (36). - С. 163-174.

[4] Приходько В.М., Строганов Д.В., Якунин П.С., Москвичев Е.С., Солнцев А.А. Аппроксимация среднеинтегральных оценок нестационарных режимов имитационных моделей сетей массового обслуживания. //Наука и образование: Электронное научно-техническое издание. - М.: МГТУ им. Баумана, 2012. № 3. DOI: 77-30569/355371.

[5] Строганов Д.В., Солнцев А.А., Якунин П.С., Батов Р.В., Карасев А.А. Влияние начальных условий и длительности моделирования на характеристики условнонестационарных процессов. //Наука и образование: Электронное научнотехническое издание. - М.: МГТУ им. Баумана, 2012. № 4. DOI: 77-30569/359132.

[6] Божко А.Н., Ивахненко А.А., Чернявский А.И., Солнцев А.А., Товкач П.А. Принятие рациональных решений при проектировании сборочных схем //Наука и образование: Электронное научно-техническое издание. - М.: МГТУ им. Баумана, 2012. № 10. DOI: 10.7463/1012.0475116 http://technomag.edu.ru/doc/475116.html.

[7] Николаев А.Б., Приходько М.В., Сатышев С.Н., Солнцев А.А., Якунин П.С. Имитационные модели оценки качества транспортного обслуживания. //Автотранспортное предприятие. -2013. - № 2. - С. 52-54.

[8] Николаев А.Б. Информационные технологии в менеджменте и транспортной логистике: учебное пособие / А.Б. Николаев, А.В. Остроух. - Saint-Louis, MO, USA: Publishing House Science and Innovation Center, 2013. - 254 c. - ISBN 978-0615-67110-9.

[9] Солнцев А.А., Ивахненко А.А. Формальное описание процессов движения комплектующих на основе управляемых сетей // Автоматизация и управление в технических системах. - 2013. - № 1(3); URL: auts.esrae.ru/3-69 (дата обращения: 19.11.2013).

[10] Солнцев А.А. Модели нечеткого ситуационного анализа при описании вложенных процессов многоцелевой деятельности дилерской сети // Автоматизация и управление в технических системах. - 2013. - № 1(3); URL: auts.esrae.ru/3-71 (дата обращения: 19.11.2013).

[11] Остроух А.В. Информационные технологии в научной и производственной деятельности / [ред. А.В. Остроух] - М: ООО "Техполиграфцентр", 2011. - 240 с. ISBN 978-5-94385-056-1.

[12] Куфтинова Н.Г. Процессно-ориентированный подход к автоматизации планирования и управления транспортировкой продукции предприятий промышленности / А.В. Остроух, Н.Г. Куфтинова // Вестник МАДИ - 2010. - Вып. 4(23). - C. 62-66.

[13] Остроух А.В. Исследование начального периода моделирования на точность среднеинтегральной оценки имитационных моделей / А.В. Остроух, А.А. 
Солнцев, Н.В. Солдатов, К.А. Новицкий, П.С. Якунин // Вестник МАДИ - 2010. Вып. 2(21). - С. 61-65.

[14] Остроух А.В. Математическая модель связей в системе диагностики электрооборудования автомобилей / А.В. Остроух, А.А. Солнцев, О.Ф. Калухов, Г.Г. Ягудаев // Вестник МАДИ - 2010. - Вып. 2(21). - С. 66-70.

[15] Приходько В.М., Солнцев А.А., Саная А.Г. Сетевая теоретико-игровая модель рациональных закупок в задаче формирования адаптивного механизма согласованных цен в схеме снабжения дилерской сети // Автоматизация и управление в технических системах. - 2013. - № 1(3); URL: auts.esrae.ru/3-70 (дата обращения: 05.09.2013).

[16] Остроух А.В., Синха Бабу Раджа Исследование информационных систем управления взаимоотношениями с поставщиками // Автоматизация и управление в технических системах. - 2013. - № 4.1; DOI: 10.12731/2306-1561-2013-4-10.

[17] Остроух А.В., Суркова Н.Е. Методы проектирования информационных систем: учебное пособие. - М.: РосНОУ, 2004. - 144 с. 